\title{
Digitotalar dysmorphism
}

INSERM

\section{Source}

INSERM. (1999). Orphanet: an online rare disease and orphan drug data base. Digitotalar dysmorphism. ORPHA:1146

Digitotalar dysmorphism, also known as distal arthrogryposis type 1 (DA1), is an autosomal dominant congenital anomaly characterized by contractures of the distal regions of the hands and feet with no facial involvement or any additional anomalies. It is the most common type of distal arthrogryposis (see this term). 